\title{
EL MODELO DE ERNST FENOLLOSA SOBRE EL ARTE Y SU IMPACTO EN COLECCIONES CHILENAS. CASO DE ESTUDIO: LA COLECCIÓN DE ESTAMPAS JAPONESAS CLÁSICAS DEL ARCHIVO CENTRAL ANDRÉS BELLO
}

\author{
Gonzalo Maire* \\ Universidad de Chile \\ ALAADA Chile
}

Este artículo examina la Colección de Estampas Japonesas Clásicas del Archivo Central Andrés Bello de la universidad de Chile desde dos cauces: primero, las condiciones de posibilidad teóricas y museales de asociación de las piezas japonesas (ukiyo-e) con otros conjuntos de objetos nacionales y europeos, a partir de los modos en que a los objetos nipones se le imponen lógicas de legibilización y experiencia; segundo, desde la caracterización de esas susodichas lógicas como modelo de conocimiento del Arte, cuyo principio autoral y categorial se encuentra en el pensamiento de Ernst Fenollosa.

Palabras Claves: Arte japonés- Colecciones Chilenas- Siglo XIX- Historia y Teoría del Arte

THE MODEL OF ERNST FENOLLOSA ABOUT ART AND ITS IMPACT ON CHILEAN COLLECTIONS. CASE STUDY: THE COLLECTION OF CLASSICAL JAPANESE STAMPS FROM

THE ANDRÉS BELLO CENTRAL ARCHIVE

This article examines the Colección de Estampas Japonesas Clásicas of the Archivo Central Andrés Bello of the Universidad de Chile from two guidelines: first, the theoretical and museographic conditions of possibility to association of Japanese pieces (ukiyo-e) with other sets of local and European objects, through the ways in which the Japanese objects are imposed with logics of legibility and experience; second, from the characterization of these logical as a model of knowledge on Art, whose authorial and categorial principle is found in Ernst Fenollosa's thought.

Keywords: Japanese art- Chilean collections- 19th century- History and Theory of Art

Artículo Recibido: 12 de Marzo de 2018

Artículo Aceptado: 23 de Mayo de 2018

\footnotetext{
*E-mail: gonzalo.maire@gmail.com
} 
«Es el resultado del juego de varias instancias, tanto individuales como sociales: el hombre que ha fabricado el objeto se ha hecho una cierta idea de él; el público, amplio o confidencial, que disfruta de él y lo recibe de una cierta manera; las instituciones a las que la sociedad concede competencias para pronunciarse sobre este tema: el museo, la crítica...». Michael Baxandall.

\section{Introducción} ntre el año 2012 y 2018 se consigan dos grandes investigaciones chilena en
torno al ukiyo e vinculadas, por cierto, a colecciones nacionales. De una
orilla, la más reciente, es la investigación multidisciplinar del Museo
Nacional de Bellas Artes a su Colección de piezas asiáticas, cuya fecha de inicio es el año 2017 y se espera su culminación el año 2018 con una inédita exposición de sus grabados y pinturas ukiyo e, entre otras piezas de su depósito. La investigadora responsable es Natalia Keller. De otra, la exploración sobre la Colección de Estampas 
Japonesas Clásicas del Archivo Central Andrés Bello de la Universidad de Chile iniciada en el año 2012 y acabada en 2017, y que se enmarcó en una investigación doctoral en Filosofía y Estética bajo mi autoría. Ambos trabajos evidenciaron, en sus primeras etapas, un problema conceptual y metodológico sobre la caracterización -casi definición- del objeto de estudio: ¿qué es el ukiyo e? La interpelación despunta varias aristas conflictivas de aproximación al objeto (orígenes, técnica, formato, significaciones y lecturas, experiencia, asociación con otras formas artísticas, etcétera) que aluden, de rebote, también al estado actual de reflexión local sobre el ukiyo e. Este artículo propone explorar estos objetos japoneses desde un solo cauce de visibilización: como piezas museales investidas de una teoría o regla de dotación de sentido ${ }^{1}$.

Restringido sólo la investigación de la Colección de Estampas Japonesas Clásicas del Archivo Central Andrés Bello de la Universidad de Chile (2017), el arqueo bibliográfico realizado sobre esta colección (custodiada desde 1978 por la institución) no arroja una definición unívoca del objeto japonés, ni una explicitación de la literatura usada para administrarla. Las razones responden no sólo a la diversidad enfoques disciplinares que se entrevén matizados en la manera en que las piezas son custodiadas y estudiadas (por ejemplo, la oscilación entre la atención a la dimensión social de las obras, la técnica o vínculo con la tradición artística, y una hipótesis sobrentendida sobre el componente representacional del ukiyo e de lo real social), los órdenes metodológicos que fundamentan la asociación de las piezas con otros conjuntos (la impronta de lo iconográfico, la valoración

\footnotetext{
${ }^{1}$ La pregunta que se ha enunciado líneas arriba, ¿qué es el ukiyo-e? no alude (inocentemente) tanto a la necesidad de proferir una definición del objeto, sino a explicaciones sobre las mediaciones históricas y conceptuales en que se sostienen tales conceptualizaciones de definición y cadena de lectura de las obras. En esa consideración, el énfasis de la pregunta está más ligada -de hecho, intencionada- en la investigación de Michael Baxandall sobre el problema de la descripción y la interpretación de los cuadros (obras), en la medida de un cuestionamiento sobre el componente heurístico -mediador- de todo saber estético-visual de una pieza artística. Inscribe el problema Michael Baxandall de la siguiente manera: «Si queremos explicar cuadros, en el sentido de exponerlos en términos de sus causas históricas, lo que realmente explicamos parece que más que el cuadro sin mediatizar es el cuadro tal y como viene considerado bajo el prisma de una descripción parcialmente interpretativa [...] En primer lugar, la naturaleza del lenguaje o conceptualización serial significa que la descripción es menos una representación del cuadro, o incluso del hecho de haber visto un cuadro, que una representación del pensamiento sobre el hecho de haber visto un cuadro. En otras palabras, estamos ante la relación entre cuadro y conceptos». En Baxandall, Michael, Modelos de intención: Sobre la explicación histórica de los cuadros, Trad. Bernárdez Sanchis, Carmen, Hermann Blume, Madrid, 1989, p. 25.

Otras referencias a la problemática, con sus matices y ampliaciones, se encuentran en Burke, Peter, «Cómo interrogar a los testimonios visuales», en Palos i Peñarroya, Joan Lluís; Carrió Invernizzi, Diana, La historia imaginada: construcciones visuales del pasado en la Época Moderna, Centro de Estudios Europa Hispánica, Madrid, 2008, pp. 29-40; Baudrillard, Jean, La ilusión y la desilusión estéticas, Monte Ávila Editores, Caracas, 1998.
} 
de las obras, las lógicas hermenéuticas aplicadas al conjunto), sino, también, a modelos de concepción del fenómeno artístico activos en la política museal que determinan los modos de aproximación y lectura de las obras, los órdenes de expectativa del objeto (lo que cabe indagar y los resultados esperables en torno de ellos) y las formas de fundamentar el propio fenómeno de lo artístico.

Me refiero con esto último, por ejemplo, el homologar (incluso, soterrar) el concepto de ukiyo e al de Estampa Japonesa, o bien, suponer que estos objetos japoneses describen e ilustran una contextualidad social bajo la forma de una mímesis o representación visual. Así, en el brevísimo estudio realizado a las piezas, a razón de la donación de la colección en el año 1978 (y desde dónde se construyó el discurso museográfico de estas obras japonesas), el director del Archivo, Alamiro de Ávila Martel, caracterizó el ukiyo e en estos términos conflictivos:

La temática es muy variada [...], las de Harunobu, de una extrema delicadeza tienen siempre la figura de una muchachita [...]: representan escenas corrientes $u$ otras de relatos legendarios, todas en un tono poético².

Y líneas más abajo, añade:

La perspectiva diferente a la europea, el frecuente enfoque de detalles y el corte de las figuras y de los ambientes y objetos, pocas veces mostrados enteros, además del empleo de las masas de color planos y múltiples, provocó la admiración y sirvió de modelo [N. del autor: en referencia al impacto que causó el ukiyo e en los artistas franceses ${ }^{3}$.

Dos cosas que apuntar sobre de Ávila Martel: primero, esta caracterización del objeto japonés sigue en pleno uso por el espacio museal universitario, en el sentido del modo categorial de comprender -leer-y delimitar el sentido de las piezas entre ellas y respecto a otras. Segundo, tal descripción hermenéutica del ukiyo e supone la tensión entre la citada amplitud temática (desde motivos representacionales de la sociedad japonesa citadina hasta imaginarios mitológicos) y los recursos de configuración estéticos, técnicos

\footnotetext{
${ }^{2}$ de Ávila Martel, Alamiro, Colección Iconográfica: II Estampas Japonesas Clásicas, Catálogo de la Biblioteca Central de la Universidad de Chile, $n^{\circ}$ 4, Santiago, 1981, p. 6.

3 Ibidem, p. 8.
} 
y visuales de obtención de resultados artísticos, que se fijan en lo figurativo, lo descriptivo y en la atención a lo real, que se evidencia en el trato a la materialidad o soporte de las obras. En otras palabras, en la colección ukiyo e de la Universidad de Chile hay un modelo epistemológico que tiende a asociar (aun cuando se visibilizan las tensiones efectivas) una determinación contextual de las obras -la circunstancia social de su producción- desde la hermenéutica de las imágenes que contienen las obras, en tanto que esferas de experiencia representacionales o testimoniales de esa coyuntura epocal. Y, sin embargo, el espacio custodio de esta colección de ukiyo e desconoce los sustentos conceptuales, metodológicos y heurísticos (acaso, autorales) que normalizan sus piezas desde esta mirada de una Historia Social del Arte, sus límites y el impacto resultante en la administración de los objetos.

Este artículo establece como su objetivo principal la examinación y detección de los elementos más destacables del modelo actual de lectura y articulación museal del objeto ukiyo e en el Archivo Central Andrés Bello. El artículo plantea la siguiente tesis: el modelo de caracterización y distribución categorial de estas piezas japonesas en esta colección chilena, corresponde a la perspectiva exegética y modeladora de Ernst Fenollosa ${ }^{4}$, quien configura el primer saber exportable en publicaciones de difusión y catálogos sobre el ukiyo e hacia finales del siglo XIX, primeras décadas del XX, y cuya médula teórica es el nexo intrínseco del objeto como resultado determinante del fenómeno social, en la medida de una derivación representacional o testimonial como imagen de lo real. Desde un punto de vista metodológico, este texto aborda una exploración cualitativa-desde la mirada filosófica y estética- las concepciones teóricas e históricas sobre el Arte que intervienen en el modelo de estudio, en su aplicación al caso japonés y la colección que se indaga.

\section{El fenómeno artístico como forma-modelo}

Que el ukiyo e-o cualquier objeto- se constituya como colección en un Museo de Arte implica dos operaciones cardinales: en primer lugar, que el nuevo cuerpo museal le es propuesto un tipo de vínculo con el concepto -la institucionalidad-del Arte; aquello estará determinado por las propias políticas e ideológicas del museo custodio, así como por

\footnotetext{
${ }^{4}$ El hecho de estudiar y caracterizar el modelo de Fenollosa como forma de referencia de significación y administración de la colección ukiyo-e de estudio, no quiere decir que exista un vínculo explícito de mediación de las políticas museales y el pensamiento fenollosiano. Lo que refiere el estado actual del modelo de Fenollosa es que el Archivo reproduce y legitima la línea de exploración abierta que se inicia con el reseñado autor $y$ ha sido desarrollada por tantos otros desde finales del siglo XIX en adelante.
} 
la propia caracterización de sí (como Museo de Artes Decorativas, Museo de Bellas Artes, Museo Oriental, Casa Museo, etcétera). En segundo momento, que las obras que ingresan al museo son proclives de ser consideradas, asociadas y dotadas de sentido -de otro modo, convertirse en entidades tremendamente dúctiles y articuladas- desde los discursos disciplinares que sostienen la política ideología del museo que las resguarda ${ }^{5}$. Aquello es posible de constatar en la aprehensión museal de la Colección de Estampas Japonesas Clásicas, un conjunto de piezas ukiyo e que conviven con obras ilustrativas, grabados y registros fotográficos de autores nacionales y europeos ${ }^{6}$, disímiles desde un punto de vista geocultural e histórico ${ }^{7}$. Y, sin embargo, desde una perspectiva política y museográfica, ese corpus polivalente de obras adoptó el nombre vinculante de Colección Iconográfica.

${ }^{5}$ Si bien el Archivo Central Andrés Bello no pertenece a la DIBAM (Dirección de Bibliotecas Archivos y Museos), indico, como botón de muestra, los lineamientos políticos e ideológicos que definen y regulan la institucionalidad de esta última, y la de los espacios asociados. La DIBAM define al Museo como un «lugar de encuentro», más bien, en el sentido de convergencia de heterogeneidades geoculturales: «El museo es un espacio privilegiado para el encuentro y la comunicación entre los seres humanos de diversas culturas y tiempos, a través de sus obras y testimonios materiales», DIBAM, Memoria, cultura y creación, Santiago, 2005, disponible en: http://www.dibam.cl/614/articles-48012_recurso_01.pdf p. 18. El Archivo universitario es deudor de esta categoría de Museo y, en ese sentido, de la ideología inseminada en la dinámica de «encuentro» $y$ «diversidad».

${ }^{6}$ Específicamente, las obras y colecciones asociadas taxonómicamente a la colección de ukiyo-e son la Colección Armando Braun Menéndez (creada en el año de 1962), que contiene aguadas, acuarelas y dibujos de la Expedición Malaspina (de cuyas autorías son José del Pozo, Fernando Bambrilla y Juan Ravenet); grabados de Nemesio Antúnez; registros de John Mark y el Atlas de la Historia Física y Política de Chile, ilustrado por Claudio Gay.

${ }^{7}$ La escisión política-ideológica del Museo es mucho más aguda en sus efectos, pues, siguiendo la reflexión de Déotte sobre la condición del Museo como un aparato (proyección), su procedimiento es el de suspender la historicidad de los objetos $-y$, en ello, su propia especificidad o autenticidad-. Lo que está en juego, según la perspectiva del autor francés, es que los museos tienen por propósito develar una suerte de «verdad específica» de los objetos que resguardan, si no, más bien, someterlos a ciertos procedimientos de organización unitaria y exportable -una estética universalizante, en sus propias palabras: «Pues el museo es un aparato que genera olvido. En consecuencia: las obras son conservadas y perduran para el futuro porque están desprendidas de cualquier identidad étnica, política, social, etc. El museo es este aparato que genera lo universal, un universal por defecto, y que encuentra, además, destinatarios (el público) que tienen la misma capacidad de juzgar estéticamente obras (lo que no quiere decir reconocerlas como lo hacen los conocedores)». En Déotte, Jean-Louis, «El museo no es un dispositivo», Trad. Correa Motta, Andrés, 2008, Disponible www.lauragonzalez.com/ImagenCultura/Deotte_2008_EIMuseoNoEsUnDispositivo.pdf, p. 10

En otro artículo sobre el problema del carácter ingenito del museo y, a partir de su efecto de olvido-suspensión, el filósofo galo indica que aquella es una puerta de entrada (por contraste o inversión) para el estudio de la especificidad de las obras desde el fenómeno museal, «Como lugar de suspensión de los dispositivos ( $\mathrm{N}$. del autor: el concepto de dispositivo corresponde al lugar para una convergencia de discursos heterogéneos y generación de nuevos saberes) de destinación teológico-político-social, [el Museo] es una institución de olvido activo, de suspensión y de puesta entre paréntesis de los efectos de dispositivo. El museo «libera» porque expone las obras reducidas a sí mismas, es decir, según su 
Las piezas ukiyo e, a través del cauce teórico estético que este texto expondrá, fueron investidas por ciertas lógicas disciplinares al uso, ordenamientos teóricos de universalización y variables discursivas y teóricas del Arte. A aquella posibilidad de incorporación de las obras japonesas y europeas en unidades y potencia de juntura ficticia se llamará «modelo». Si la Colección de Estampas Japonesas Clásicas y la Colección Iconográfica sintomatizan un modelo, este involucra la existencia de uno o varios paradigmas, es decir, condiciones de posibilidad -su estatuto arquetípico, si se quiere-para la emergencia y transformación de los discursos disciplinares que intervienen en el Museo, como la demarcación de la Verdad y lo conocible en su estado actual. El historiador de las Ciencias, Thomas Kuhn, caracterizará al modelo y su ligadura con el paradigma de esta manera:

Por una parte, [Paradigma] significa toda la constelación de creencias, valores, técnicas, etc., que comparten los miembros de una comunidad dada. Por otra parte, denota una especie de elemento de tal constelación, las concretas soluciones de problemas que, empleadas como modelos o ejemplos pueden remplazar reglas explícitas como base de la solución de los restantes problemas de la ciencia normals.

Si bien el pensamiento de Kuhn está abocado a las Ciencias Naturales, Física y Matemáticas, su impronta se expandió profundamente en la naturaleza propia del saber. De este modo, el Arte y el Museo, y en un sentido más amplio, el fenómeno artístico, se halla entrecruzado históricamente por paradigmas y modelos de comprensión de lo artístico desde su condición de praxis y teoría. El esteta polaco, Wladyslaw Tatarkiewicz, advirtió esta situación desde el estudio de las transformaciones del concepto de Arte -y aquellas nociones colindantes, como la Forma, la Representación, la Belleza, etcétera-, a partir de un método lógico analítico. El autor despliega en su obra Historia de seis ideas: arte, belleza, forma, creatividad, mímesis, experiencia estética (2001), tres distinciones en las transformaciones del concepto de Arte, a través de su historia; a) la constante redefinición de la categoría de Arte, b) la reformulación de las relaciones entre los objetos

literalidad». En Déotte, Jean-Louis, «La temporalidad de los aparatos modernos», La época de los aparatos, Trad. Oviedo, Antonio, Adriana Hidalgo, Buenos Aires, 2013, p. 286.

${ }^{8}$ Kuhn, Thomas S., La estructura de las revoluciones científicas, Trad. Contin, Agustín, Fondo de Cultura Económica, Buenos Aires, 2004, p. 13. 
que ingresan -o son exiliados- de aquella categoría y, c) los modos en que ciertas disciplinas generan una adecuación para el estudio de esos objetos como elementos partícipes del concepto de Arte ${ }^{9}$. Tatarkiewicz conjetura lo siguiente en el prefacio:

La historia de la estética, igual que las historias de otras ciencias, puede considerarse de dos modos: como la historia de los hombres que crearon el campo de estudio, o como la historia de los problemas que han surgido y se han resuelto en el curso de su empresa10.

El ukiyo e (o como fue catalogada la colección del Archivo Andrés Bello, «estampas japonesas clásicas») es referenciado como un cuerpo dentro del Arte, vale decir, un tipo de objeto artístico inscrito en un museo o espacio museal dedicado a piezas artísticas; lo que envuelve que las piezas son sometidas a tales dinámicas categoriales y de configuración de experiencia. El asunto que se debe caracterizar, primero, es el conducto heurístico histórico que produce la traslación de lo artístico en el ukiyo e (objeto material japonés) en el reducto del espacio museal (formulación europea de valoración y acopio de obras de Arte).

\section{La condición de posibilidad de la política museal de la Colección de Estampas Japonesas}

\section{Clásicas: su adscripción al fenómeno del orientalismo}

Articular un vínculo de aprehensión de la colección ukiyo e chilena de estudio a partir de las directrices del modelo que Ernst Fenollosa elaboró sus particulares concepciones de lo artístico, requiere -como estado preliminar de significatividad-caracterizar un conducto de posibilidad en que el fenómeno artístico japonés pueda ingresar a la fisionomía museal y artística, a la vez que, visibilizar a nivel autoral (en el propio Fenollosa) las condiciones de germinación, institución y reproducción de un modelo de saber sobre lo

\footnotetext{
${ }^{9}$ Además de Wladyslaw Tatarkiewicz indico, al menos, tres autores que, directa o tangencialmente, han desarrollado sus investigaciones en torno a la ductilidad y maleabilidad del concepto de Arte, a contramano de posiciones unitarias, progresistas o evolucionistas del Arte y de la Historia del Arte. Primero, vid. Fernández, Carlos Arturo, Concepto de arte e idea de progreso en la historia del arte, Universidad de Antioquia, Medellín, 2008. Luego, Didi-Huberman, Georges, Ante el tiempo: historia del arte y anacronismo de las imágenes, Trad. Oviedo, Antonio, Adriana Hidalgo Editora, Buenos Aires, 2011 y, finalmente, Aumont, Jacques, La Estética hoy, Trad. Galmarini, Marco Aurelio, Ediciones Cátedra, Madrid, 1998.

10 Tatarkiewicz, Wladyslaw, Historia de seis ideas: arte, belleza, forma, creatividad, mímesis, experiencia estética, Trad. Rodríguez Martín, Francisco, Tecnos, Madrid, 2001, p. 25.
} 
artístico (japonés) en el espacio del Museo local. Aquello interpela dos puntos teórico históricos específicos: de una orilla, cimentar un conducto de compartición histórica del fenómeno artístico asiático japonés como si fuese un correlato del Arte europeo; de otra, delinear la dinámica de institucionalización del campo del Museo en Japón, respecto a calibrar el ukiyo e desde el pensamiento actualizado (o importado) de Ernst Fenollosa sobre el Arte.

El primer punto está entretejido con el fenómeno del Poder y la ontologización histórica que se da a la constelación de Oriente, al modo que lo conjetura Edward Said (Orientalismo, 1978). En Orientalismo, la relación del saber que se fabula desde una dicotomía inicial entre Occidente y Oriente es la de un ejercicio de Poder y dominación sobre una forma de otredad o ilegibilidad. Tal dinámica es un choque de imposiciones desde un bloque activo y configurador - lo que, sin precisarse en su totalidad, designa Occidente $^{11}$ - hacia una pasividad territorial que, desde un estadio pre crítico, no es capaz de conocerse a sí misma -la otredad, también sinuosa, de Oriente-. En ese escenario, uno de los elementos más provocativos que desarrolla Said, en términos de lógicas disciplinares, es la hipótesis de un calce epistemológico entre los discursos que ciñen al orientalismo y sus objetos de estudio. Un ejercicio de normativización que es dispuesto en clave de negatividad: como peligro, sospecha, coerción, delimitación e interdicto de las condiciones de posibilidad del saber sobre Oriente:

\begin{abstract}
Mejor que hacer una lista de todas las figuras del discurso que se asocian a Oriente su extrañeza, su diferencia, su sensualidad exótica... -podemos generalizar sobre ellas viendo cómo se transmitieron a través del Renacimiento. Son declarativas y evidentes [...] transmiten una impresión de repetición y de firmeza,
\end{abstract}

\footnotetext{
${ }^{11}$ Si bien la propia geografía y sustancia de lo llamado como Occidente es un asunto ríspido y propenso a inagotables debates, ya sea desde un punto de vista político, geográfico, cultural. Véase, por ejemplo, la obra de Dussel, Enrique, Hacia los orígenes de Occidente: meditaciones semitas, Kanankil Editorial, México, 2012. A efectos de este texto, se entenderá por Occidente la descripción general que ofrece Michel Foucault: "Si, cuando digo Occidente, sabe, es una palabra vaga, desagradable de utilizar y casi indispensable. Quiero decir que muchas cosas, muchas prácticas sociales, prácticas políticas, practicas económicas, nacieron y se desarrollaron, con una fuerza enorme, es una especie de región geográfica que se sitúa entre el Vístula y Gibraltar, entre las costas del norte de Escocia y la punta de Italia». En Foucault, Michel, El poder, una bestia magnifica: sobre el poder, la prisión y la vida, Trad. Pons, Horacio, Siglo Veintiuno Editores, Buenos Aires, 2012, p. 31
} 


\section{son siempre simétricas [...] Para todas estas funciones,}

frecuentemente es suficiente con emplear la palabra es ${ }^{12}$.

En la conjugación del verbo ser-Oriente es-Said insemina la articulación con el Poder desde un desplazamiento letal en el sujeto que conoce y produce un saber sobre su objeto; golpea el carácter constructivo, y en ello, de artificio, de la generación de todo conocimiento a una privativa seña de verdad, esto es, de universalidad: el orientalismo anula la mediatez de la representación y ancora la experiencia de Oriente en la inmediatez de la presentación. Dice el autor: «la labor de cualquier orientalista es confirmar Oriente ante los ojos de sus lectores, jamás pretende ni intenta perturbar las sólidas convicciones que ya tienen» ${ }^{13}$.

El caso de la sostenida importación de saberes occidentales y calce de sus discursos a la realidad local es lo que acontece en Japón durante la última parte del siglo XIX y los comienzos del siglo XX. Por cierto que concurrió un proceso mucho más abarcador, lo que habitualmente se ha denominado la occidentalización japonesa del Periodo Meiji, pero, en lo que concierne a lo artístico, se gestó la inoculación y determinación de un conjunto de horizontes teóricos y paradigmáticos que propiciaron la institucionalidad del Museo y Academias de Arte en Japón ${ }^{14}$. Su sedimento nuclear consistió en la configuración de un concepto operativo de Arte y Obra, aplicable al fenómeno japonés. Su forma más distintiva es el proceso de separación de la producción artística entre las nociones de Las Bellas Artes (bijutsu) y Arte, en el sentido técnico y más tradicional (geijutsu). A propósito de los alcances y efectos, en el artículo «Okakura Tenshin y Fenollosa» (2001) del filósofo japonés Katarani Kōjin, se lee lo siguiente:

All these disciplines were able to survive is due only to their reorganization into western categories of knowledge. Even if people

\footnotetext{
${ }^{12}$ Said, Edward, Orientalismo, Trad. Fuentes, María Luisa, Editorial Debolsillo, Barcelona, 2015, p. 13.

13 Ibidem, p. 100.

${ }^{14}$ La ruptura de Japón con el Estado bakufu -el denominado feudalismo japonés- y su tentativa de reproducir el concepto de Estado occidental imperante supuso la aparición de la institucionalidad del Arte, en parte, como la fundación de museos en un doble propósito: configuración de exposiciones y curatorías, y la emergencia sostenida, en torno a un cariz político-nacional, de los museos nacionales, Almazán, David, «La occidentalización de oriente (y al revés): una aproximación a los museos de arte contemporáneo de Japón», Museología, crítica y Arte contemporáneo, Prensas Universitarias de Zaragoza, Zaragoza, 2003.
} 


\section{later began to search for marks of local distinction, this process took place within a western framework ${ }^{15}$.}

En esta coyuntura social, política y artística, un autor de especial atención es el crítico de Arte estadounidense Ernst Fenollosa. No sólo en lo tocante a un intento de preservación -lo diré así- de sesgo «patrimonial» de una producción artística japonesa, como también, en la creación de instancias asociativas e institucionales para el resguardo de una suerte de sustancialidad japonesa. Si se revisan las publicaciones de Fenollosa, tanto en Japón como las editadas en el extranjero, aquellas han sido una bisagra entre el campo de la Estética, la Teoría del Arte, la Historia del Arte y el Museo, a la par de sus actividades de incentivo y cuidado de la susodicha cifra japonesa: la creación de un Museo Nacional, un Comité para la Protección de Propiedades Culturales y el decreto oficial de la Escuela de Bellas Artes de Tōkyō ${ }^{16}$. En el pensamiento fenollosiano hay una pretensión de confeccionar un relato de la experiencia de las obras y su contexto, en el sentido de fijar principios y condiciones de legibilidad y autenticidad del fenómeno artístico japonés, que han nutrido un horizonte de lectura convencionalizado del ukiyo e, y vigente todavía en la colección chilena de estudio.

\section{El modelo de Ernst Fenollosa sobre el Arte: caso ukiyo-e}

El trabajo teórico de Fenollosa en Japón está disgregado entre artículos, conferencias y publicaciones variadas en prensa internacional como japonesa. Sin embargo, su mayor empresa reflexiva se encuentra en el libro póstumo Epochs of Chinese and Japanese Art: an outline History of East Asiatic design, publicado por su viuda, Mary Fenollosa, en 1921. La publicación intentó generar una-si no, la primera-gran Historia del Arte de China y Japón donde, evidentemente, el ukiyo e tiene un apartado dentro de aquel corpus orgánico de arrimo al fenómeno artístico. La Colección de Estampas Japonesas Clásicas recoge en su estado administrativo y de documentación dos vectores del modelo del autor norteamericano: la categoría de obra y la relación privilegiada de los objetos artístico con la sociedad, que Fenollosa con cierta insistencia traslada hacia el campo museal.

Ahora bien, la primera particularidad del libro es de doble atención: de una parte, la condición de las obras japonesas (incluido, por el supuesto, el ukiyo e) y su posibilidad

\footnotetext{
${ }^{15}$ Kōjin, Katarani, «Okakura Tenshin y Fenollosa», en F. Marra, Michael, A History of Modern Japanese Aesthetics, University of Hawaii Press, Hawaii, 2001, p. 43.

${ }^{16}$ Cabañas Moreno, Pilar, «Bigaku: sobre los comienzos de la crítica de arte y la teoría estética en Japón», Anales de Historia del Arte, vol. 9, Universidad Complutense, Madrid, 1999 (pp. 367-381).
} 
de generar un conocimiento, fue concebido desde el presupuesto que son sintomáticas (o bien, explicativas) de una suerte de desarrollo civilizatorio del ser humano tipificadamente japonés -si cabe decirlo, a través de este descriptor geográfico y etnográfico-17; de otra, desde la propia construcción de una Historia del Arte, Fenollosa coloca un énfasis en el carácter potencial de exportación de la producción japonesa hacia el mundo. Me refiero con esto último, primero, a pensar desde los discursos historiográficos una fuente exportable de objetos de valor para un público de coleccionistas; segundo, desde un punto de vista disciplinar del Arte, que aquel material artístico es posible de ser interrogado desde «fuera» de su nicho histórico y social, o bien, ser homologado a la tradición europea (es decir, que puede ser pensado como Arte). En la Introducción del susodicho libro póstumo, el autor inicia su declaración de propósitos con lo siguiente:

\section{The purpose of this book is to contribute first hand material towards a real history of East Asiatic Art, yet in a, interesting way that may appeal, not only to scholars, but to art collectors, general readers on Oriental topics, and travellers in Asia ${ }^{18}$.}

En este propósito de la publicación se extrae un núcleo de concomitancia cardinal entre el Museo y la Obra ${ }^{19}$, entre el espacio museal y el fenómeno artístico japonés: Fenollosa elabora un modelo de comportamiento del Arte que taxonomiza el fenómeno

\footnotetext{
${ }^{17}$ A colación saco una distinción que percibió Fenollosa del fenómeno artístico japonés en la forma de una específica sensibilidad frente a lo real, por ejemplo, cuando expresó una comparativa de figuración y experiencia de un modelo de árbol: «Take a look at Kōrin's painting of a plum tree. Would you take it for a natural plum tree? Of course not! And yet you would not change a bit of it. That is because the painting possesses the idea of the plum». En Kaneda, Tamio, «Fenollosa and Tsubouchi Shōyō», en F. Marra, Michael, A History of Modern Japanese Aesthetics, University of Hawaii Press, Hawaii, 2001, p. 60.

$\mathrm{Y}$, sin embargo, independientemente de aquellas especificidades formales o estéticas, desde un punto de vista analítico el fenómeno artístico japonés podía ser reflexionado bajo los mismos marcos conceptuales del arte occidental, vid. Foxwell, Chelsea, Making modern Japanese-style Painting: Kano Hogai and the search for images, University of Chicago Press, Chicago, 2015.

${ }^{18}$ Fenollosa, Ernst, Epochs of Chinese and Japanese Art: an outline History of East Asiatic design, Willian Heinemann, London, 1921, p. 35.

${ }^{19}$ Esta articulación, hoy, en el campo de la Museografía está completamente instalada a nivel global. En el caso chileno, lo que fue la DIBAM y el actual Ministerio de las Culturas, las Artes y el Patrimonio, poseen protocolos que fundamentan la labor del museo y sus colecciones como instancias de difusión, conocimiento y reflexión: «La documentación de bienes culturales es una labor compleja de gestión de la colección, necesita de tiempo y raramente puede finalizarse: es una actividad constante, para la cual se necesita de los procesos de registro, inventario y catalogación del objeto, los cuales incluyen, además, la búsqueda y recopilación de la documentación existente, la revisión de esa información, y el incremento constante de esta misma en el soporte apropiado». En Nagel, Lina, "Registro y Documentación”, Manual de Registro y Documentación de Bienes Culturales, Andros Impresores, Santiago, 2008, p. 8.
} 
japonés hacia una grilla que estandariza, por analogía, rendimientos y solidaridades artística estéticas con la tradición europea vigente, a saber, a partir del paradigma de las Bellas Artes (que ya se desperdigada como una categoría en Japón con la denominación de Bijutsu $^{2 \mathcal{G}}$. El autor sostiene y fuerza la tesis que el fenómeno artístico japonés puede ser calibrado y conjeturado como si se tratase del Arte occidental, pues, por una parte, declara la existencia de obras artísticas (la producción japonesa es apuntada en ese contenedor); de otra, la mentada producción es calibrada como dispositivos testimoniales -registros o archivos legítimos-del medio social en que son generados. Por fuera de todo debate, hablar del ukiyo e es tratar pre críticamente con objetos artísticos desde enfoques y metodológicas provenientes del Arte. El autor estadounidense expresa esta asociación cardinal con anterioridad, en un artículo publicado durante 1893 para referirse cualitativamente a rasgos estéticos y nacionales de la producción artística japonesa: «A nation's art is more than its technical methods, or an aggregate of its collections; it is the flower of its spiritual life - the breathing out upon its world the flavor of its inward conceptions of man and nature» ${ }^{21}$. Ambos elementos, la Obra y la fuerza de la contextualidad que se ejerce en ellas, constituyen el modelo fenollosiano que la colección ukiyo e de estudio chilena acusa recibo para poder administrar y significar musealmente las piezas.

\section{El concepto de Obra en el modelo de Ernst Fenollosa sobre el ukiyo-e}

El primer elemento que configura el modelo fenollosiano -su noción de Obra que aplicará a la producción japonesa- se gesta desde un entrecruce con la postura del arqueólogo Edward S. Morse, mirando de reojo la obra de Charles Darwin. Como tesis primeriza, para Fenollosa ontológicamente la Obra es una analogía al concepto de organismo vivo darwiniano y su mediación o impacto con el entorno natural ${ }^{22}$. Así, pues,

\footnotetext{
${ }^{20}$ Yuko Kikuchi indica, a propósito de la institución y circulación del término en Japón: «The term bijutsu was officially used in 1873 when Japan exhibited at the Vienna International Exhibition, with a broad concept including arts in general, music, painting, sculpture and poetry [...]. However, the definitions of the terms bijutsu and kogei were gradually consolidated and developed in a Japanese way through the establishment of modern institutional systems including museums, exhibition, art schools and art journalism». En Kikuchi, Yuko, Japanese modernisation and Mingei Theory: Cultural Nationalism and Oriental Orientalism, Routledge, London, 2004, p. 81.

${ }^{21}$ Fenollosa, Ernst, "An outline of Japanese art", The Century Magazine, The Century Company, New York, 1893 (pp. 62-75).

${ }^{22}$ Fenollosa desde el año 1788 comienza a impartir clases en la Universidad de Tōkyō, donde su pensamiento se empieza a decantar en un traspaso del método darwiniano hacia un calce con el fenómeno social. Particularmente, en el creciente interés por la obra de Helbert Spencer. Ese nutrimiento conceptual se expresa, apretadamente, desde la siguiente cita del filósofo inglés: «Concerning the present position of the human race, we must therefore say, that man needed one moral constitution to fit him for his original
} 
de igual forma como el entorno determina, vía adaptabilidad (la capacidad de adecuarse y abrirse paso a través del entorno) y variabilidad (un transformismo ingénito), la constitución de los organismos, Fenollosa pretende transportarlo a la esfera de la sociedad. En el texto de Darwin On the Origins of Species (1909) se encuentra el antecedente directo:

The direct action of changed conditions leads to definite or indefinite results. In the latter case the organisation [sic] seems to become plastic, and we have much fluctuating variability. In the former case the nature of the organism is such that it yields readily, when subjected to certain conditions, and all, or nearly all, the individuals become modified in the same way ${ }^{23}$.

Lo medular del fragmento, a la luz del modelo de Ernst Fenollosa: el crítico de arte supondrá que acontece un transformismo del objeto del Arte en el tiempo y el espacio; vale decir, asienta en la Obra artística un componente genealógico y teleológico, pero, al mismo tiempo, muy delimitado en su campo de despliegue. Lo genealógico no se extiende a través de la asociación de la multiplicidad de objetos artísticos -japoneses- (no es propiamente la verificación de una historia de las obras lo que concibe), sino, más bien, acontece en la posibilidad de rastrear en cada una de ellas -desde sí y por sí mismas- un testimonio civilizatorio del ser humano como un movimiento desde lo estético hacia lo antropológico. Esa presentación civilizatoria de la Obra está ancorada, de sopetón, en su inclusión al Museo, según se indicaba en los propósitos de su libro. Este hecho no es del todo aislado ni carente de vigencia hoy por hoy. Precisamente parte de la caracterización actual del ukiyo eque utiliza la colección de estudio - en buena medida, orientando su estudio sobre la obra editada Maestros de la Estampa Japonesa: su mundo y su obra de Richard Lane-, ancora a las «estampas japonesas» en una dinámica configurativa visible e inyectada en lo geográfico y civilizatorio (la «tradición japonesa»):

Los maestros del ukiyo e representan una conclusión adecuada de la prolongada y ardiente tradición del arte clásico japonés. Como la época que lo nutre -el Período Edo (1600 1868)-, el arte del ukiyo e representa un movimiento único en Japón: el desarrollo de un

state; that he needs another to fit him for his present state; and that he has been, is, and will long continue to be, in process of adaptation». En Spencer, Herbert, Social Statics, John Chapman, London, 1851, p. 43. ${ }^{23}$ Darwin, Charles, The origins of Species, P.F. Collier, New York, 1909, p. 131. 


\section{gran renacimiento que se basa principalmente en fuentes populares $^{24}$.}

La coordenada civilizatoria también se anuncia en publicaciones contemporáneas del fenómeno del Museo, que rigen las políticas y técnicas de la institución que custodia: por ejemplo, en el Cataloging Cultural Object, una guía para el estudio del patrimonio cultural a nivel contemporáneo, esta fuerza testimonial se conjuga en la terminología del artefacto: «Cultural artifacts are physical objects produced or shaped by human craft, especially tools, weapons, ornaments, or other items that inherently give cultural clues about the person (and culture) who made or used them» ${ }^{25}$. Si se acoplara la discusión fenollosiana a las categorías y esquemas museales del siglo XXI, para Ernst Fenollosa la Obra es la forma de un artefacto $\mathrm{y}$, por ende, la condición para pensar la producción artística japonesa análogamente a la europea. Es en la condición de artefacto como objeto revelador de una especificidad cultural pasada (en otras palabras, en tanto que un archivo) que la colección de Estampas Japonesas Clásicas puede establecerse desde una mínima reciprocidad con otros conjuntos de piezas polivalentes histórica, cultural y espacialmente 26 : las piezas, en toda su polivalencia cultural e histórica, remiten a un valor fuera de sí, cuyo principio es el de ser dispositivos de representación -mediación-. La propia institución, pues, es un

${ }^{24}$ Lane, Richard, Maestros de la Estampa Japonesa: su mundo y su obra, traducción de José Antonio Rico, Editorial Herrero, México, 1962, p. 7.

${ }_{25}$ Baca, Murtha, Cataloging Cultural Objects: A Guide to Describing Cultural Works and Their Images, American Library Association, Chicago, 2006, p. 5.

${ }^{26}$ Este nexo entre el concepto de artefacto (testimonio cultural material en sí mismo) y archivo (lo que testimonia o registra fuera de sí) el Archivo Andrés Bello lo anuda en sus propios criterios de catalogación, a saber, la insistencia de lo figurativo o ilustrativo como elemento cohesionador y definidor de los objetos: «La primera parte de esta donación la componen acuarelas, dibujos y aguadas de dibujantes que acompañan la llamada «Expedición Malaspina» que recorre parte importante de los territorios dominados por la corona española, estas labores de registro quedan a cargo de José del Pozo, Fernando Bambrilla y Juan Ravenet, a ellos se suman las láminas de Benoit-Henry Darondeau quien fuera parte, primero como cirujano y luego dibujante de la expedición Le Bonite, Auguste Borges, Alphonse Giast con registros que fueran comprados a otro coleccionista, el argentino Bonifacio del Carril, piezas que se encargan de detallar por un lado el paisaje que se puede apreciar a lo largo de Chile en esos años, y por otro la caracterización de tipos populares [...]. De una manera muy distinta nos encontramos con otro grupo de obras pertenecientes a artistas dedicados principalmente al grabado, en una dimensión absolutamente distinta a la que se hacía hasta ese entonces en Chile, aquella de carácter más bien figurativo, así gracias a Nemesio Antúnez recién llegado de Nueva York [...] Completan esta colección las «estampas japonesas» donadas en 1979, que según Alamiro de Ávila «representan escenas corrientes u otras de relatos legendarios, todas en un tono poético» con piezas que van desde el siglo XVII al XIX». En Archivo Central Andrés Bello, Colección Iconográfica, Registro Guía, revisado en enero de 2018. Disponible en:

http://archivobello.uchile.cl/content/Registro\%20Guia/2016/enero/registro_guia_coleccion_iconografica.p df. 
Archivo que resguarda cúmulos de objetos que ontológicamente son formas o potencias de observancia de lo humano.

Desde esta caracterización cardinal y elemental, el modelo del Arte fenollosiano se expande hacia una comprensión del espacio tiempo, esto es, hacia un modo de configuración de las obras en el relato disciplinar como núcleos «epidérmicos» de un contenido por fuera de ellas. Aquella es la primera fuente de sentido y principio de conocimiento museal que se extrae de la Colección de Estampas Japonesas Clásicas: hay un sedimento externo que configura las posibilidades de variabilidad de la producción artística, dependiendo de la coyuntura específica; y una pieza de museo no es, si no, la expresión visual y de significación de aquella adecuación continua. Esto se precisa con mayor agudeza en el caso del ukiyo e, pues, para Ernst Fenollosa, la propia determinación estética y formal de estas obras descansan en la fuerza de su contextualidad. Por ende, el primero esbozo de arrimo que se aprecia sobre estos objetos en el autor es un problema de distinción de su indicador de variabilidad, esto es, la forma en que se expresa la forma de producción visual del ukiyo e, en tanto que sentido de experimentación:

Again it is often made out that this Ukiyoye [sic] is primarily a school of printed art, and is treated as if it included all book illustration. The truth is that, on the one hand, it is as much primarily a school of painting as is the shijo; and that, on the other, much of Japanese book illustration belongs to Shijo art and to the work of the Kano pupils of Tanyu. This is only another illustration of the aesthetic confusion that issues from classifying through industrial methods ${ }^{27}$.

La pregunta fundamental en esta (aparente) ambivalencia entre si las Obras ukiyo e son correspondientes a un concepto de Escuela (de Pintura) y o si su caracterización está ceñida a la producción de impresiones (el hecho de su formato), radica en el sentido que Fenollosa asigna a la propia noción de Escuela. Desde los pilares teóricos darwnianos que administra Fenollosa, la Obra no se basta por sí misma para explicar -o, más bien, para poder sintetizar una lectura- de la especificidad artística o estética de una cultura. El modelo fenollosiano expresa la necesidad de un principio conductor entre la forma del artefacto y un nutrimiento social como un segundo eje de problematización. Por fuera del trabajo de Darwin, este nuevo vector se halla en una de las tesis de Herbert Spencer (autor

${ }^{27}$ Fenollosa, Ernst, Epochs of Chinese..., op. cit., p. 179. 
ya reseñado que Fenollosa leía, estudiaba y enseñaba en la Universidad de Tōkyō). Spencer desarrolla sobre la relación de la producción humana -y el mismo ser humano-, respecto a su forma de habitar mundo, la siguiente tesis: «Men cannot break that vital law of the social organism [...] Being themselves members of the community, they are affected by whatever affects it» ${ }^{28}$. La trayectoria del modelo fenollosiano para estudiar el fenómeno artístico japonés es una extensión del pensamiento darwiniano -como se advierte en la conjugación organismo entorno hacia la fórmula de organismo sociedad-, esto es, en cponderar la relación de los cuerpos artísticos con el entorno en una dinámica de dependencia y transformación. Es aquella ecuación vital desde donde el ukiyo e adquiere una fisionomía consolidada para la administración museal local.

\section{Ukiyo-e y el testimonio de lo social: la forma de la Escuela y su significación en el museo}

El modelo fenollosiano impugna a la obra -el ukiyo e- en presuponer que su experiencia y valía está dada por un tipo de nutrimiento que lo propicia en contenido y forma analizable del devenir del ser humano ${ }^{29}$; aquel sedimento son los imaginarios, discursos y repertorios visuales vinculantes a los chōnin (los «hombres de ciudad»; actores sociales que surgirían en los primeros años del siglo XVII en Japón), articulados en no más de unas cuantas ciudades (Kyōto, Edo, Ōsaka). Pero, además, para Fenollosa el nexo y el modo de configuración entre la conjunción social y la obra -es decir, su componente heurístico- está dado por el concepto de Escuela, al que asigna un triple nicho de compresibilidad: es un espacio de transferencia de rasgos personales (elementos estilísticos) entre autoría individual, también en referencia con sus pares y, finalmente, en mediación con el contexto social en que ellos se desarrollan ${ }^{30}$. Dos consignaciones importantes, a tal

\footnotetext{
${ }^{28}$ Spencer, Herbert, op. cit., p. 269.

29 De otro modo, Fenollosa apela en la obra un sentido inmediato: el imperativo que la obra debe «decir algo», y cuyo origen de «ese algo» está fuera de sus límites. Esta suposición se sostiene en la siguiente reclamación: «puesto que todos los lenguajes son por definición construcciones formales, el lenguaje formal del arte también debe estar imbuido de contenido social». En Eisenman, Stephen F., Historia crítica del arte del siglo XIX, Ediciones AKAL, Madrid, 2001, p. 14.

${ }^{30}$ Sin ir más lejos del punto, un autor contemporáneo de Fenollosa, Hippolyte Taine, consolida esta relación troncal entre Arte-Sociedad desde una estética tremendamente empiricista, al suponer que la exploración y el producto del Arte está determinado con la coyuntura exclusiva del autor. De otro modo, el Arte es un espacio epidérmico de la cultura material y simbólica de las sociedades: «Everywhere may be found similar examples of the alliance, the intimate harmony existing between an artist and his contemporaries; and we may rest assured that if we desire to comprehend the taste or the genius of an artist, the reasons leading him to choose a particular style of painting drama, to prefer this or that character or coloring, and to represent particular sentiments, we must seek for them in the social and intellectual
} 
efecto. La primera, es que en Fenollosa la Escuela recoge - a modo de registro- ese vector social desde la propia constitución del ukiyo e como obra artística (definición de lo que es): son objetos que, bajo la forma de una ejemplariedad, reproducen el nexo arte sociedad como imágenes testimoniales, descriptivas o mediadoras; en suma, cargadas de iconografía y sentido iconográfico. De allí, en el caso de estudio, que la institución custodia ponga el énfasis en lo iconográfico como matriz valorativa y asociativa de la Colección de Estampas Japonesas Clásicas y lo demás conjuntos articulados. Lo segundo, guarda relación con el sitial que adquiere el concepto de Escuela, respecto al movimiento de desarrollo cultural civilizatorio que Fenollosa entrevé en el caso japonés. Ese es un lugar complejo de indagar, pero, vital en los resultados para el Archivo Central Andrés Bello: Fenollosa categoriza la obra como artefacto desde rangos temporales tremendamente amplios y donde los márgenes y objetos de lo contextual son elásticos y generales (sus discursos, imaginarios, espacios sociales, etcétera), por ejemplo, en la categoría de Primitive Art, que apela, en este caso, el periodo neolítico japonés. Sin embargo, progresivamente su esquema periodizador se va angostando y enfocando a contenidos y esquemas concretos, mientras que las obras artísticas se van fabulando como archivos de registro, tal es el caso del periodo Social Art, o bien, el lugar de inscripción del ukiyo e: Modern plebeian art in Kioto, The Shijo school y Modern plebeian art in Yedo [sic]. Ukiyo ye [sic]. La justificación y culminación del binomio obra sociedad se conjura en el ukiyo e, a partir de la siguiente montura:

There are millions of ways of combining these many kinds of beauty and these many species of suggestion; the history of art records the ways heretofore tried. But in all these efforts we find some sort of order, due to the similarity of effort in the human spirit and in the incidence of the social environment ${ }^{31}$.

El efecto es inmediato, irrenunciable y tenaz para Fenollosa y el museo custodio de la Colección de Estampas Japonesas Clásicas: el ukiyo e está construido valorativamente y desde un componente heurístico que lo lee como una forma de Representación reforzada: obras que son imágenes que se configuran desde un referente de lo real (la cotidianidad de ciertos espacios urbanos y grupos sociales), e imágenes que son portadoras de una saturación contextual (el contenido y el continente de las obras son sintomáticos de una

conditions of the community in the midst of which he lived». En Taine, Hippolyte, Philosophy of Art, Trad. Durand, John, Holt \& Williams, New York, 1873, p. 27.

${ }^{31}$ Fenollosa, Ernst, Epochs of Chinese..., op., cit., p. 25. 
estructura determinativa). En tanto que referente de la realidad, el modelo de Fenollosa radicaliza el testimonio -el documento o artefacto- hacia lo figurativo, ilustrativo, o bien, lo mimético. Precisamente, la mediación con lo real se expresa en una intención por la forma figurativa (el hecho de recoger y conformar una «vista de lo cotidiano»). En cuanto a la saturación, el concepto de Escuela fenollosiano es un intento de ordenar taxonómicamente la historia social de la producción artística japonesa en segmentos autónomos y sincrónicos -en la medida de presentarse en una progresión, cada periodo y Escuela suponen la ruptura con los periodos anteriores o lugares contemporáneos-. Así, el ukiyo e como sumatoria de escuelas ${ }^{32}$ es una distinción de la Escuela Yamato e, o bien, de la Escuela Tosa o la Escuela Kanō.

Finalmente, la experiencia de la obra es un punto importante, respecto a la formulación de Fenollosa sobre la Escuela: el ukiyo e como conjunto de escuelas queda determinado a una hermenéutica social y, en la forma de la gobernabilidad de las piezas en el Museo, lo social se presenta como el Sentido último y pleno de documentación, registro y asociación de las piezas. Esta concepción fenollosiana es recitada hasta hoy, por ejemplo, como se indica en la caracterización del ukiyo e en el trabajo de Stephen Addiss:

Ukiyo, the «floating world» was originally a Buddhist term, referring to the transient nature of human life and experience [...] In the hedonistic urban culture of Early Modern Japan, however, the concept of a «floating world» was given a new twist. The new spirit proclaimed that if pleasures are only momentary, then let's enjoy them as much as possible when they appear ${ }^{33}$.

O bien, también puede advertirse en las anotaciones y comentarios de Richard Lane: Para el ciudadano recientemente liberado, hijo del renacimiento japonés del siglo XVII, "el mundo flotante" tiende a perder sus características de transitoriedad de un mundo de ilusión para adoptar las implicaciones hedonísticas de un nuevo ambiente

\footnotetext{
${ }^{32}$ En el catálogo de la primera exhibición de ukiyo-e en Estados Unidos, Ernst Fenollosa ofrece la siguiente definición del ukiyo-e: «Ukioye [sic] is a school of Japanese painting and print designing, which for the last three centuries has been the special organ of expression for the common people». En Fenollosa, Ernst, The masters of Ukioye. W.H. Ketcham, New York, 1896, p. 1.

33 Marks, Andreas, Japanese woodblock prints: artists, publishers and masterworks, 1680-1900, Tuttle Publishing, North Clarendon, 2010, p. 9.
} 
estilizado por el placer: un mundo de mujeres fáciles, de alegres actores y de todos los placeres de la carne34.

Hippolyte Taine refuerza esta perspectiva determinista de Fenollosa, pues, sostiene que el modo de lectura -dar una explicación cientificista- de las obras configura, por principio, esquemas de organización y taxonomización de las piezas universales, de tal suerte que el nexo Arte-Sociedad deviene ineludiblemente, también, en una forma de modelo de administración del objeto como pieza de museo: la Colección de Estampas Japonesas Clásicas y la Colección Iconográfica (el espacio de confluencia de todas las colecciones) sólo tiene su fundamento de existencia, precisamente, en el descriptor de lo Iconográfico, es decir, en su capacidad de ordenar las formas hermenéuticas de determinación de lo contextual en modos de administración museográfica. Aquel es el principio de asociación y juntura de tal polivalencia geocultural de los objetos custodios y, por cierto, el sentido de Obra y Arte que Fenollosa rescata soterradamente de Taine: «I mean works of art arranged by families in galleries and libraries, like plants in an herbarium, and animals in a museum» 35 .

\section{Conclusiones}

Según lo desarrollado en este artículo, las conclusiones se encauzan desde dos tipos lineamientos que poseen, más que nada, la constatación primeriza de dos problemáticas abiertas. Lo primero, desde una mirada más abarcadora, es el modo en que los espacios museales -y, en particular, el del caso de estudio-construyen sus esquemas de significación y administración de sus colecciones; es decir, elaboran la documentación y sus políticas museales. En ese sentido, la articulación del fenómeno artístico (ya sea en la territorialidad del Museo, el ejercicio de la documentación o desde las incursiones estéticas y teóricas) es siempre la mediación que se construye entre la figura del investigador (o una institución) y el problema que enfrenta con las piezas. No es casual ni azaroso el hecho de cómo se ha constituido la Colección Iconográfica -la naturaleza de sus objetos y el llamamiento que hacen en su asociación-, pues, está entrecruzado por la documentación existente del Archivo y sus fuentes bibliográficas o teóricas de configuración de lectura, en este caso, de las piezas japonesas. En este sentido, el ukiyo e inevitablemente está ungido por la trayectoria de documentación del espacio museal (que, como se ha desarrollado, no es ni sistemática ni sobre la base de bibliografía actual), y por el propio juego de adecuación de

${ }^{34}$ Lane, Richard, Maestros de la estampa japonesa..., op. cit., p.10.

35 Taine, Hippolyte, Philosophy of Art, op. cit., p. 39. 
estos objetos japoneses a una coyuntura de colecciones nacionales y, en términos generales, de cifra «occidental».

En el caso de la colección chilena de ukiyo e, la política museal ha adoptado un modelo museográfico (o, si quiere, una heurística estética) de aprehensión de estas piezas, cuya base está en la capacidad de asociarse con otros objetos de diversa procedencia geocultural y, en ello, imponiendo en el objeto japonés ciertos principios de legibilidad: por una parte, son obras que testimonian visualmente estadios civilizatorios del lugar de procedencia -artefactos- y están, de otra parte, determinadas por su coyuntura social e histórica. En un tono similar, aquello ya fue expuesto por Michael Baxandall, respecto de la experiencia de la obra artística y los procesos hermenéuticos que, de ella, se desencadenan:

La naturaleza del lenguaje o conceptualización serial significa que la descripción es menos una representación del cuatro, o incluso del hecho de haber visto un cuadro, que una representación del pensamiento sobre el hecho de haber visto un cuadro. En otras palabras, estamos ante la relación entre cuadro y conceptos ${ }^{36}$.

La segunda problemática que afecta a la colección de estudio está en relación con los fundamentos y contenidos de aquel modelo de legibilidad que ha adoptado actívamente: la huella de Ernst Fenollosa como el impacto que tiene su concepción del fenómeno artístico y tensión crítica en la operatividad de las obras (la posibilidad de dar un sentido a las piezas) en el contexto museal. Quiérase o no, la colección chilena ha sido documentada y elaborada, a través de fuentes secundarias, editadas, que, con recurrencia reproducen por su carácter general, lógicas fenollosianas, pues, él fue uno de los primeros autores en modelar un conocimiento disciplinar sobre el arte japonés desde una mirada occidental europea (por ejemplo, los citados trabajos de Richard Lane o Stephen Addiss, sin nombrar, acaso, la única investigación oficial de la colección chilena, elaborada por Alamiro de Ávila Martel). El pensamiento de Fenollosa, por lo menos sobre el ukiyo e, mantiene una vigencia en el caso chileno, a partir de la insistencia que las piezas están definidas por el entrecruce Obra, Imagen y Sociedad como un nudo afianzado en la hermenéutica de sus imágenes. Sólo es posible en la insistencia de esta triada -que, si se quiere, se decanta en la solicitud de la obra como una Representación de lo real- que la Colección de Estampas Japonesas

${ }^{36}$ Baxandall, Michael, op. cit., p. 25.

INTUS-LEGERE HISTORIA/ ISSN 0718-5456| EISSN 0719-8949/Año 2018, Vol. 12, № 1, pp. 114-138. 
Clásicas de la Universidad de Chile esté en convivencia bajo una misma norma y experiencia museal estética con piezas de grabados europeos del siglo XIX, acuarelas, registros e ilustraciones de carácter geográficos e instrumentales. 


\section{Bibliografía.}

- Almazán, David, «La occidentalización de oriente (y al revés): una aproximación a los museos de arte contemporáneo de Japón», en Museología, crítica y Arte contemporáneo, Prensas Universitarias de Zaragoza, Zaragoza, 2003.

- Archivo Central Andrés Bello, Colección Iconográfica, Registro Guía, revisado en enero de 2018, url: http://archivobello.uchile.cl/content/Registro\%20Guia/2016/enero/regi stro_guia_coleccion_iconografica.pdf

- Aumont, Jacques, La Estética hoy, Trad. Galmarini, Marco Aurelio, Madrid, Ediciones Cátedra, 1998.

- BACA, Murtha, Cataloging Cultural Objects: A Guide to Describing Cultural Works and Their Images, American Library Association, Chicago, 2006.

- Baudrillard, Jean, La ilusión y la desilusión estéticas, Monte Ávila Editores, Caracas, 1998.

- BaXAndall, Michael, Modelos de intención: Sobre la explicación histórica de los cuadros, Trad. Bernárdez Sanchis, Carmen, Hermann Blume, Madrid, 1989.

- Burke, Peter, «Cómo interrogar a los testimonios visuales», en Palos i Peñarroya, Joan Lluís; Carrió Invernizzi, Diana, La historia imaginada: construcciones visuales del pasado en la Época Moderna, Centro de Estudios Europa Hispánica, Madrid, 2008, pp. 29 40.

- Cabañas Moreno, Pilar, "Bigaku: Sobre los comienzos de la crítica de arte y la teoría estética en Japón", en Anales de Historia del Arte, volumen 9, Universidad Complutense, Madrid, 1999, pp. 367 381.

- Darwin, Charles, The origins of Species, P.F. Collier, New York, 1909.

- DE Ávila MarTel, Alamiro, Colección Iconográfica: II Estampas Japonesas Clásicas, Catálogo de la Biblioteca Central de la Universidad de Chile, número 4, Santiago, 1981 
- DÉOTTE, Jean Louis, "La temporalidad de los aparatos modernos», en La época de los aparatos, traducción de Antonio Oviedo Buenos Aires, Adriana Hidalgo, 2013.

Andrés, 2008 , «El museo no es un dispositivo", Trad. Correa Motta, www.lauragonzalez.com/ImagenCultura/Deotte_2008_ElMuseoNoEsUnD ispositivo.pdf

- DiBAM, Memoria, cultura y creación, Santiago, 2005, url: http://www.dibam.cl/614/articles 48012_recurso_01.pdf

- Didi Huberman, Georges, Ante el tiempo: historia del arte y anacronismo de las imágenes, Trad. y nota preliminar Oviedo, Antonio, Buenos Aires, Adriana Hidalgo Editora, 2011.

- Dussel, Enrique, Hacia los orígenes de Occidente: meditaciones semitas, Kanankil Editorial, México, 2012.

- Eisenman, Stephen F., Historia crítica del arte del siglo XIX, Madrid, Ediciones AKAL, 2001.

- Fenollosa, Ernst, "An outline of Japanese art”, en The Century Magazine, New York, The Century Company, 1893, pp. 62 75.

- _ Epochs of Chinese and Japanese Art: an outline History of East Asiatic design, London, Willian Heinemann, 1921.

- — The masters of Ukioye, W.H. Ketcham, New York, 1896.

- Fernández, Carlos Arturo, Concepto de arte e idea de progreso en la historia del arte, Medellín, Universidad de Antioquia, 2008.

- Foucault, Michel, El poder, una bestia magnifica: sobre el poder, la prisión y la vida, trad. Pons, Horacio, Siglo Veintiuno Editores, Buenos Aires, 2012.

- Foxwell, Chelsea, Making modern Japanese style Painting: Kano Hogai and the search for images, University of Chicago Press, Chicago, 2015.

- Kaneda Tamio, «Fenollosa and Tsubouchi Shōyō», en F. Marra, Michael, $A$ History of Modern Japanese Aesthetics, University of Hawaii Press, Hawaii, 2001. 
- Katarani Kōjin, «Okakura Tenshin y Fenollosa», en F. Marra, Michael, $A$ History of Modern Japanese Aesthetics, University of Hawaii Press, Hawaii, 2001.

- Kikuchi, Yuko, Japanese modernisation and Mingei Theory: Cultural Nationalism and Oriental Orientalism, London, Routledge, 2004.

- Kunn, Thomas S., La estructura de las revoluciones científicas, Trad. Contin, Agustín, Fondo de Cultura Económica, Buenos Aires, 2004.

- LANe, Richard, Maestros de la Estampa Japonesa: su mundo y su obra, Trad. Rico, José Antonio, México, Editorial Herrero, 1962.

- MARks, Andreas, Japanese woodblock prints: artists, publishers and masterworks, 1680 1900, North Clarendon, Tuttle Publishing, 2010.

- NAGel, Lina, "Registro y Documentación", en Manual de Registro y Documentación de Bienes Culturales, Andros Impresores, Santiago, 2008.

- SAID, Edward, Orientalismo, Trad. Fuentes, María Luisa, Editorial Debolsillo, Barcelona, 2015.

- SPEnCER, Herbert, Social Statics. John Chapmanpp, London, 1851.

- $\quad$ Taine, Hippolyte, Philosophy of Art, Trad. Durand, John, New York, Holt \& Williams, 1873.

- Tatarkiewicz, Wladyslaw, Historia de seis ideas: arte, belleza, forma, creatividad, mímesis, experiencia estética, Trad. Rodríguez Martín, Francisco, Tecnos, Madrid, 2001. 